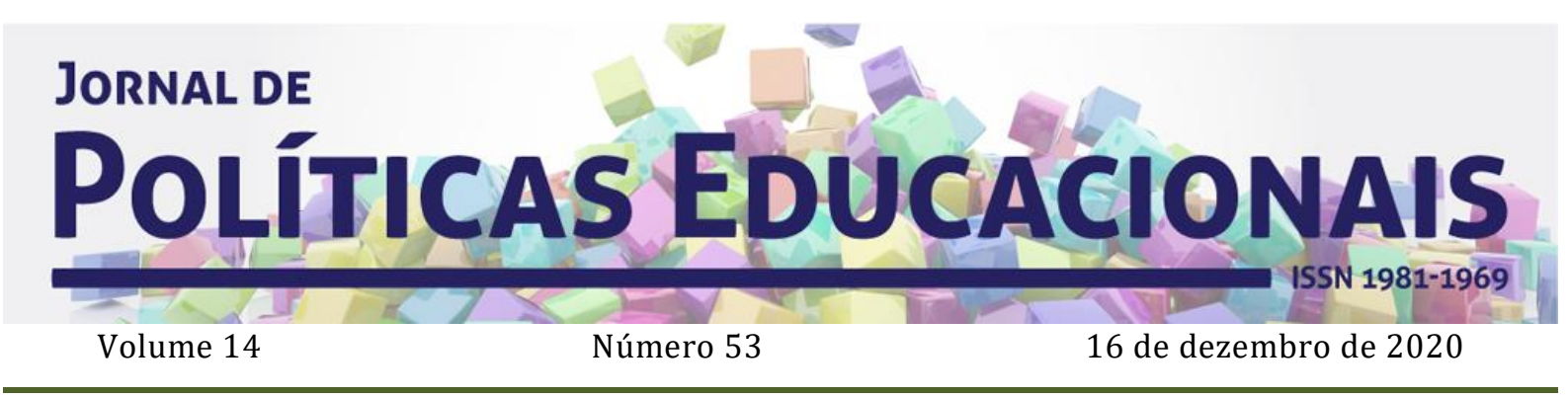

\title{
0 direito à educação na ordem constitucional brasileira: texto e contexto
}

\section{The right to education in the Brazilian constitutional order: text and context}

\section{El derecho a la educación en el orden constitucional brasileño: texto y contexto}

\author{
Marli dos Santos de Oliveira ${ }^{1}$ \\ Igor Henrique da Silva Santelli ${ }^{2}$
}

Citação: OLIVEIRA, M. dos S. de; SANTELLI, I. H. da S. O direito à educação na ordem constitucional brasileira: texto e contexto. Jornal de Políticas Educacionais. V. 14, n. 53. Dezembro de 2020.

http://10.5380/jpe.v14i0.77550

\section{Resumo}

0 presente trabalho tem por objetivo geral analisar o direito à educação no cenário constitucional brasileiro a partir dos direitos consagrados nas constituições, respectivamente. 0 estudo foi realizado por meio de pesquisa bibliográfica e documental, sobretudo a partir da análise da legislação correlata aos direitos sociais, especialmente às atinentes ao direito à educação. Nota-se que a educação figura como direito fundamental de natureza social no ordenamento jurídico brasileiro, cuja constituição enquanto um direito situa-se num contexto de permanente disputa por projetos distintos de sociedade, principalmente nos aspectos relacionados à sua prestação enquanto serviço público e sua universalização enquanto direito de todos e dever do Estado.

Palavras-chave: Constituição Federal de 1988, Direitos sociais, Direito à educação.

\section{Abstract}

The present work has the general objective of analyzing the right to education in the Brazilian constitutional scenario from the rights enshrined in the constitutions, respectively. The study was carried out through bibliographic and documentary research, mainly from the analysis of the legislation related to social rights, especially those related to the right to education. It should be noted that education appears as a fundamental

\footnotetext{
${ }^{1}$ Doutora em Educação pela Universidade Federal de Mato Grosso do Sul (UFMS). Pedagoga do Instituto Fedeeral de Educação e Tecnologia do Mato Grosso do Sul (IFMS). Ponta Porã, MS, Brasil. Orcid: http://orcid.org/0000-0003-1440-9045 E-mail: marli.oliveiras@hotmail.com 2 Mestre em Direito Processual e Cidadania pela Universidade Paranaense. Pós-graduado em Direito, com especialização em Direitos Humanos e Cidadania, pela Universidade Federal da Grande Dourados. Orcid: http://orcid.org/0000-0001-7336-8090. E-mail: igorsantelli@hotmail.com
} 
right of a social nature in the Brazilian legal system, whose constitution as a right is situated in a context of permanent dispute for different projects of society, mainly in aspects related to its provision as a public service and its universalization as the right of all and the duty of the State.

Keywords: Federal Constitution of 1988; Social rights; Right to education.

\section{Resumen}

El presente trabajo tiene el objetivo general de analizar el derecho a la educación en el escenario constitucional brasileño a partir de los derechos consagrados en las constituciones, respectivamente. El estudio se realizó mediante una investigación bibliográfica y documental, principalmente a partir del análisis de la legislación relacionada con los derechos sociales, especialmente los relacionados con el derecho a la educación. Cabe señalar que la educación aparece como un derecho fundamental de carácter social en el ordenamiento jurídico brasileño, cuya constitución como derecho se sitúa en un contexto de permanente disputa por diferentes proyectos de la sociedad, principalmente en aspectos relacionados con su prestación como servicio público y su universalización. como un derecho de todos y un deber del Estado. Palabras clave: 1988 Constitución Federal, Derechos Sociales, Derecho a la Educación.

\section{Considerações iniciais}

Diferentes áreas do conhecimento, sobretudo as Ciências Sociais Aplicadas e Ciências Humanas, (re) direcionam seus objetos de análise a fim de analisar os fenômenos sociais e educacionais no contexto da promulgação da “Constituição Cidadã”, realizada em 1988.

No bojo de seus princípios fundamentais, a Constituição da República Federativa do Brasil de 1988 (CF/1988) estabelece que a República Federativa do Brasil se constitui em Estado Democrático de Direito, cujos fundamentos são a soberania, a cidadania, a dignidade da pessoa humana, os valores sociais do trabalho, bem como o pluralismo político.

0 título de Constituição Cidadã advém, entre outros aspectos, pelo rol estabelecido em seu Título II "Dos Direitos e Garantias Fundamentais”, cujos Art. 5o e Art. 6o, especialmente, preconizam taxativamente garantias fundamentais individuais e coletivas, bem como o rol de direitos sociais, cuja previsão constitucional representa uma conquista histórica.

Nesse contexto, busca-se compreender as prerrogativas constitucionais destinadas ao Direito à Educação enquanto um direito social constitucionalmente garantido. A premissa é que a previsão da educação enquanto direito social apresenta-se como inegável avanço no campo das políticas sociais, no entanto, há disputas permanentes que implicam em retrocessos no tocante aos direitos sociais em geral e, em particular, à educação. 
Nessa perspectiva, o presente texto tem como objetivo geral analisar o Direito à Educação no cenário constitucional brasileira no intuito de compreender os desdobramentos, embates, debates e perspectivas em torno do Direito à Educação no Brasil. Entende-se que as manifestações jurídicas, sociais, educacionais, políticas e econômicas em âmbito nacional não se dissociam do universal, embora apresentem características e contornos próprios, em cada espaço e momento histórico específico.

Dessa forma, o alcance dos objetivos aqui propostos exige a pesquisa documental por meio de levantamento e análise de atos normativos e legislações oriundas do governo federal, particularmente aquelas atinentes à CF/1988 e ao Direito à Educação. A pesquisa documental assume uma função precípua visto recorrer a fontes diversificadas e sem tratamento analítico, como relatórios, documentos oficiais, tabelas e dados estatísticos, dentre outros documentos fundamentais com vistas à compreensão do objeto de estudo.

Além do aporte documental, realiza-se pesquisa bibliográfica a fim de verificar as discussões doutrinárias acerca do tema a fim de subsidiar as reflexões e análises aqui propostas, sobretudo as relacionadas à educação enquanto um direito fundamental social.

\section{Direito à educação no contexto das constituições brasileiras: caminhos percorridos}

A compreensão da educação como um direito e prática social exige, de certo modo, a análise da legislação referente a tal dimensão da vida social. Essa análise é fundamental - embora não suficiente - com vistas ao conhecimento dos estímulos (intervenção afirmativa) e limitações (intervenção negativa) do Estado às práticas sociais de modo geral e, em particular, à educação.

Tanto a ausência como a presença de determinada lei na prática social são igualmente significativas na medida em que ambas indicam conflito de interesses. "Assim, a análise do significado social de determinado corpo de leis só se completa com a abordagem dos conflitos de interesses subjacentes à sua elaboração e à sua aplicação nas relações sociais concretas" (NOGUEIRA, 2012, p. 10).

O direito à educação, no contexto das constituições dos Estados burgueses modernos, tende a ser expressamente declarado como um direito dos cidadãos. 0 que difere são suas variáveis de extensão, alcance, profundidade e de precisão desse direito constitucionalmente consagrado. Fundamentalmente, essa variação se justifica pelos 
conflitos de interesses por projetos distintos de sociedade, nos diferentes contextos sociais (NOGUEIRA, 2012).

A fim de situar o direito à educação na ordem constitucional brasileira, apresentase a tabela 01 a seguir com vistas a demonstrar alguns aspectos gerais e, posteriormente, alguns estímulos e limites no tocante ao direito à educação em cada uma das Constituições:

Tabela 01: Informações gerais sobre as Constituições do Brasil.

\begin{tabular}{cccc}
\hline Constituiçães Brasileiras & Fim de vigência & $\begin{array}{c}\text { Número de } \\
\text { Emendas }\end{array}$ & Duração \\
\hline $\begin{array}{c}\text { Constituição de 1824 } \\
\text { (Brasil Império) }\end{array}$ & 1889 & 1 & 65 anos \\
\hline $\begin{array}{c}\text { Constituição de 1891 } \\
\text { (Brasil República) }\end{array}$ & 1930 & 1 & 39 anos \\
\hline $\begin{array}{c}\text { Constituição de 1934 } \\
\text { (Segunda República) }\end{array}$ & 1937 & 1 & 3 anos \\
\hline $\begin{array}{c}\text { Constituição de 1937 } \\
\text { (Estado Novo) }\end{array}$ & 1945 & 21 & 21 anos \\
\hline $\begin{array}{c}\text { Constituição de 1946 } \\
\text { (Redemocratização) }\end{array}$ & 1967 & 27 & 20 anos \\
\hline $\begin{array}{c}\text { Constituição de 1967 } \\
\text { (Regime Militar) }\end{array}$ & 1987 & 26 & - \\
\hline $\begin{array}{c}\text { Constituição de 1988 } \\
\text { (Constituição Cidadã) }\end{array}$ & Em vigor & $108^{3}$ & \\
\hline
\end{tabular}

Fonte: Elaboração própria com base em Nogueira (2012), Brasil (2019).

Ao ser reconhecido como um direito fundamental do homem, o direito à educação é consagrado na constituição e em demais legislações infraconstitucionais brasileiras. A primeira constituição do Brasil independente de Portugal - a Imperial de 1824 - traz aspectos gerais e poucas indicações sobre educação. No rol dos Direitos do Cidadão, nos termos do Art. 179, apresenta que a inviolabilidade dos direitos civis e políticos dos cidadãos brasileiros, que tem por base a liberdade, a segurança individual e a propriedade é garantida pela instrução primária gratuita a todos os cidadãos.

Sobre essa declaração é importante destacar, sobretudo, dois aspectos: a gratuidade e os cidadãos a quem o direito à educação se destinava. Em primeiro lugar, embora o Brasil tenha sido um dos primeiros países do mundo a declará-lo como gratuito, o Poder Público não empreendeu esforços a fim de torná-lo acessível enquanto uma política pública. Em segundo lugar, a abrangência do conceito de cidadão era demasiada

\footnotetext{
3 Dados relativos à consulta realizada em 17 de setembro de 2020 no endereço: <http://www.planalto.gov.br/ccivil_03/constituicao/emendas/emc/quadro_emc.htm>.
} 
restrita, visto que a maioria da população brasileira se constituía de escravos. Por consequência, o acesso à escola e os beneficiários do direito à educação restou prejudicado durante o período imperial (OLIVEIRA, 2002).

A Constituição de 1891 implementou-se no contexto de proclamação da República e, de modo similar, dispôs sobre o direito à educação no Título IV, Seção II - Declaração de Direitos. Trouxe a laicidade do ensino público, mas não afirmou que a educação seria obrigatória a todos. Desse modo, as Constituições de 1824 e 1891, embora tenham abarcado a educação em seu texto, não a definiram como uma obrigação a ser cumprido pelo estado, qualificando o acesso à educação elementar como um direito individual do cidadão.

No contexto dos anos de 1930, houve muitas disputas em torno dos direitos sociais, na medida em que a Revolução de 1930 trouxe a ideia de modernização do país e o estímulo à nacionalidade. 0 país começa um processo de crescimento econômico acelerado, dando início às primeiras estruturas burocráticas de administração pública no Brasil. 0 período iniciado em 1930 representa os anos em que profundas transformações ocorreram no Estado brasileiro: da inexistência do Estado Oligárquico à hegemonia do setor industrial (IANNI, 1996).

Nesse contexto, o Manifesto dos Pioneiros da Educação Nova, lançado em 1932 em preparação a Assembleia Nacional Constituinte de 1933, sob o título "A reconstrução educacional no Brasil: ao povo e ao governo", é considerado como o marco inicial com vistas a um projeto nacional de educação. O lançamento do Manifesto no contexto da década de 1930 representa um momento histórico de disputas, cujos avanços em torno da proposição e materialização de planos nacionais de educação reverberaram nitidamente na trajetória do planejamento educacional brasileiro, a saber: a) liderança do movimento de educadores na proposta de construção de um Plano Nacional de Educação cuja forma e expressão se dão em uma Conferência Nacional de Educação em 1932; b) ênfase na organicidade e visão sistêmica de educação como alternativa as reformas fragmentadas e regionalizadas; c) afirmação do direito à educação e dever do Estado em oferece-la a todos; d) caráter eminentemente público da escola, com base nos princípios da laicidade, gratuidade e obrigatoriedade; e) necessidade de gestão e aplicação de recursos próprios ao desenvolvimento educacional; f) regime de colaboração para superação do centralismo estéril; g) articulação entre sistema e plano no contexto da organização da educação brasileira (BORDIGNON, QUEIROZ, GOMES, 2011). 
Algumas dessas necessidades apontadas no Manifesto foram contempladas na Constituição de 1934 ao dispor em seu Art.149:

A educação é direito de todos e deve ser ministrada pela família e pelos Poderes Públicos, cumprindo a estes proporcioná-la a brasileiros e a estrangeiros domiciliados no País, de modo que possibilite eficientes fatores da vida moral e econômica da Nação, e desenvolva num espírito brasileiro a consciência da solidariedade humana (BRASIL, 2005).

Á época, o debate constituinte direcionava-se à definição de qual seria a instituição responsável pela educação: família ou Estado e, nesse contexto, coube ao Estado criar as condições para sua efetivação enquanto que à família coube a escolha acerca do tipo de educação. Ao subentender-se que escolha do tipo de educação era primazia da família, criou-se condições para o estabelecimento de escolas particulares com subvenção do Estado (OLIVEIRA, 2002).

Além de declarar a educação como direito de todos, a Constituição de 1934 estabeleceu em seu art. 150 as competências da União na elaboração de normas gerais e do Plano Nacional de Educação com vistas a declarar a extensão desse direito. Embora tenha vigorado por pouco mais de três anos, a Constituição de 1934 é considerada como uma referência fundamental no tocante ao direito à educação cujas polaridades políticas e debates educacionais figuram até os dias de hoje, sobretudo no que concerne à destinação de recursos públicos educacionais aos setores privados.

O período compreendido entre 1930 a 1945, sob o governo de Getúlio Vargas adotou uma série de medidas econômicas que representaram, de modo expresso, uma nova fase nas relações entre o Estado e o sistema político econômico. Decretada por Getúlio Vargas após o golpe de novembro de 1937, a Constituição de 1937 estruturou-se de forma que a definição de responsabilidades educacionais se encontrava nas disposições relativas à família nos termos do art. 125: a educação integral da prole é o primeiro dever e o direito natural dos pais. 0 Estado não será estranho a esse dever, colaborando, de maneira principal ou subsidiária, para facilitar a sua execução ou suprir as deficiências e lacunas da educação particular (BRASIL, 2005).

O direito à educação, nessa época, priorizava a escola particular, e ao Estado cabia um papel subsidiário na tarefa de educar. Ao conceber que a educação era um direito natural dos pais, omite-se o direito da criança enquanto um sujeito de direitos, visto que o subordina ao dos seus responsáveis. 
Nos anos de 1940, os esforços governamentais eram no sentido de planificar para organizar os processos orçamentários e as prioridades econômicas. (FONSECA, 2016). Nesse momento histórico, deve-se analisar as ações voltadas ao contexto educacional sob a premissa de que o poder público se organizou e passou a funcionar de modo acentuado, de acordo com as exigências e possibilidades estabelecidas pelo sistema capitalista vigente. Dessa forma, [...] "os governantes passaram a reformular as condições de funcionamento do mercado de fatores de produção (ou forças produtivas), bem como as relações internas de produção, e as relações entre a economia brasileira e a economia internacional" (IANNI, 1996, p.26).

A retomada dos ideais do Manifesto dos Pioneiros da Educação se deu no retorno do período democrático em $1945^{4}$ com a realização do IX Congresso Brasileiro de Educação, cujos objetivos direcionavam-se ao estudo e planejamento da educação nacional. A Constituição ditatorial de 1937 foi substituída pela Constituição de 1946 elaborada a partir de Assembleia Nacional Constituinte. Diferentemente dos ideais nacionalistas de Vargas, "a Constituição de 1946 e as normas políticas e econômicas adotadas pelos governantes instauraram a hegemonia dos princípios da "livre iniciativa" e da "igualdade de oportunidades para nacionais e estrangeiros" (IANNI, 1996, p.92).

A Constituição de 1946 que vigorou por muitos anos, retomou muitos temas educacionais trazidos pela Constituição de 1934 e declarou, em seu art. 166, que a educação é um direito de todos e será dada no lar e na escola, inspirada nos princípios de liberdade e nos ideais de solidariedade humana.

Art. 168. A legislação do ensino adotará os seguintes princípios: I - o ensino primário é obrigatório e só será dado na língua nacional; II- o ensino primário oficial é gratuito para todos; o ensino oficial ulterior ao primário sê-lo-á para quantos provarem falta ou insuficiência de recursos (BRASIL, 2005).

Como se nota, a gratuidade do ensino primário é assegurada, mas o acesso gratuito aos níveis mais altos de ensino condiciona-se a comprovação de insuficiência de recursos financeiros. De certa forma, a gratuidade nesse contexto pode ser vista como uma exceção

\footnotetext{
${ }^{4}$ Em 29 de outubro de 1945 o ditador Getúlio Vargas foi deposto, em um Golpe de Estado organizado por forças políticas civis e militares. Em seguida, iniciou-se um programa de desmantelamento de quase tudo que estivesse identificado com a ditadura do Estado Novo e a figura de Vargas. A própria estrutura do Estado passou a ser reformulada, devido à decisão dos novos governantes de "redemocratizar" o País (IANNI, 1996, p.85).
} 
OLIVEIRA, M. dos S. de; SANTELLI, I. H. da S. O direito à educação na ordem constitucional brasileira: texto e contexto

se considerado o texto Constitucional de 1934, pois a progressiva gratuidade e a própria constituição do direito à educação pressupõem sua integralidade e generalização, seja aos níveis elementares como superiores de ensino.

No sucedâneo, no governo de Jânio Quadros (1961) o debate sobre a Lei de Diretrizes e Bases da Educação Nacional estava em pauta no Congresso Nacional, cujos confrontos envolvendo privatistas e publicistas, laicidade e ensino religioso, liberais e conservadores, etc. e o próprio teor do planejamento educacional constituíam focos de divergências (BORDIGNON, QUEIROZ, GOMES, 2011).

Em 20 de dezembro de 1961 aprovou-se a primeira Lei de Diretrizes e Bases da Educação Nacional (LDB), Lei no 4.024 que em termos de legislação infraconstitucional, foi o primeiro texto legal a estabelecer a educação enquanto direito e dever, nos seguintes termos:

0 direito à educação é assegurado:

I- Pela obrigação do poder e público e pela liberdade de iniciativa particular de ministrarem o ensino em todos os graus, na forma da lei em vigor;

II- Pela obrigação do Estado de fornecer recursos indispensáveis para que a família e, na falta desta, os demais membros da sociedade se desobriguem dos encargos da educação, quando provada a insuficiência de meios, de modo que sejam asseguradas iguais oportunidades a todos (BRASIL, 1961, grifo nosso).

A LDB sancionada em 1961, após 13 (treze) anos de disputas no Congresso e na sociedade civil, deteve de dois momentos singulares e importantes em sua tramitação. 0 primeiro, deu-se no âmbito da Câmara, cujas disputas relacionava-se a maior ou menor presença da União na sua relação com os Estados. 0 segundo momento, no contexto da sociedade civil: projetos públicos versus projetos privados.

0 projeto final sancionado harmonizou esses dois momentos, dispondo sobre a gratuidade, a obrigatoriedade, a vinculação orçamentária dentre outros pontos, incluindo as demandas do ensino privado com a possibilidade de recursos públicos e o ensino religioso nas escolas oficiais (CURY, 2008).

Outro aspecto importante, retomado pela LDB de 1961, refere-se à necessidade de elaboração de um Plano Nacional de Educação, função atribuída ao Conselho Federal de Educação (criado pela LDB em substituição ao então Conselho Nacional de Educação). Cumprindo suas funções, o Conselho elaborou e enviou, em 1962, o Plano Nacional de Educação que definia metas para o período de 1963 a 1970. 
OLIVEIRA, M. dos S. de; SANTELLI, I. H. da S. O direito à educação na ordem constitucional brasileira: texto e contexto

Logo após a entrega do Plano Nacional de Educação ao Ministério da Educação, a equipe do Ministério do Planejamento elaborou, ainda em 1962, o Plano Trienal de Desenvolvimento (1963-1965) com o intuito de manter as taxas de crescimento e reduzir a inflação. Abandonou-se o Plano então elaborado pelo Ministério da Educação, e o Ministério de Planejamento elaborou seu Plano Trienal de Educação (1963-1965).

Segundo Ianni (1996), o Plano Trienal de Desenvolvimento foi o primeiro instrumento de política econômica global e globalizante, em comparação com os governos anteriores. Continha um diagnóstico amplo, integrado, fatores e perspectivas da economia do país, cuja formulação encontrara um clima político favorável criado pela Carta de Punta del Este5, em 1961.

Com o golpe civil-militar de 19646, a LDB vai sendo desarticulada pela hegemonia do pensamento tecnocrático e pelas reformas desencadeadas nos governos militares. 0 aparato tecnocrático do Estado estruturou e institucionalizou as formas de atender às demandas sociais, tendo o setor econômico como norteador do planejamento e, consequentemente, das políticas setoriais (MARTINS, PIMENTA, 2013).

Na ditadura civil-militar, inicialmente mantida nos limites da Constituição de 1946, teve-se de modo recorrente medidas de exceção e isso implicou na necessidade de outro ordenamento jurídico com vistas às práticas e valores então praticados. Assim, outorgase a Constituição de 1967 que tratou da educação escolar nos seguintes termos:

A educação é direito de todos e será dada no lar e na escola; assegurada a igualdade de oportunidades, deve inspirar-se no princípio da unidade nacional e nos ideais de liberdade e de solidariedade humana [...]

§3ํ- A legislação do ensino adotará os seguintes princípios e normas: [...] II- o ensino dos sete aos quatorze anos é obrigatório para todos e gratuito nos estabelecimentos primários oficiais;

III- o ensino oficial ulterior ao primário será, igualmente, gratuito para quantos, demonstrando efetivo aproveitamento, provarem falta ou insuficiência de recursos. Sempre que possível, o Poder Público

\footnotetext{
${ }^{5}$ Denominação pela qual ficou conhecida a VIII Reunião de Consulta dos Ministros das Relações Exteriores da Organização dos Estados Americanos (OEA), realizada em Punta del Este, Uruguai, entre 22 e 31 de janeiro de 1962. A reunião teve como objetivo central discutir o impacto da Revolução Cubana nos assuntos hemisféricos, evidenciando divergências de atitude e encaminhamento entre o Brasil e os EUA.

6 [...] Durante os anos 1964-1983 as políticas econômicas governamentais beneficiaram-se de uma estrutura política excepcional. Devido à vigência dos atos institucionais foi implantada a hegemonia absoluta do Poder Executivo sobre o Poder Legislativo. Isto é, os atos institucionais impuseram-se por sobre os dispositivos da Constituição de 1946. Nos anos de 1967-69 adotou-se uma Constituição que manteve os poderes excepcionais do Executivo. Além disso, em dezembro de 1968 foi decretado o Ato Institucional no 5, conferindo novas prerrogativas ao Presidente da República, em detrimento dos outros poderes. Em fins de 1967, ainda, o governo adotou nova constituição, na qual se consolidam os poderes excepcionais do Executivo (IANNI, 1996, p. 230-231).
} 
OLIVEIRA, M. dos S. de; SANTELLI, I. H. da S. O direito à educação na ordem constitucional

substituirá o regime de gratuidade pelo de concessão de bolsas de estudo, exigido o posterior reembolso no caso de ensino de grau superior (BRASIL, 2005).

Houve a ampliação do período de escolarização obrigatória, isso é, dos 7 (sete) aos 14 (quatorze) anos, no contexto do ensino primário ${ }^{7}$. No que se refere ao inciso III, embora retome a temática presente nos textos constitucionais de 1937 e 1946 em relação à gratuidade de ensino ulterior ao primário àqueles que comprovassem insuficiências de recursos financeiros, introduziu-se uma novidade no sentido de bolsas restituíveis, considerada como a origem do crédito educativo no ensino superior (OLIVEIRA, 2002).

Houve a supressão da vinculação entre o financiamento da educação escolar e a porcentagem da receita resultante de impostos, além da determinação da União enquanto ente competente para estabelecer planos nacionais de educação, bem como as diretrizes e bases da educação nacional (Art. 8ㅜ, XVII).

A Emenda Constitucional no 1 de 1969, também conhecida como Constituição de 1969, provocou alterações e reconheceu, pela primeira vez em nível constitucional, a “educação como direito de todos e dever do estado" (art. 176).

Ianni (1996) aponta que os governos dos anos 1964-1985, isso é, dos governos de Castello Branco, Costa e Silva, Garrastazu Médici, Ernesto Geisel e João Figueiredo direcionaram suas políticas econômicas no intuito de reduzir a taxa de inflação, incentivar a exportação de produto, racionalizar o sistema tributário e fiscal, estimular, sob controle governamental, o mercado de capitais e a entrada de capital e tecnologia estrangeiros, dentre outros direcionamentos.

Com vistas ao alcance desses objetivos econômicos, teve início um processo mais consistente de planejamento governamental expresso nos Planos Nacionais de Desenvolvimento (PND). Notadamente na área da educação, elaborou-se 03 (três) Planos Setoriais de Educação e Cultura (PSEC) correspondentes ao mesmo período dos PND, quais sejam: I PND (1972-1974): I PSEC; II PND (1975-1979): II PSEC; III PND (19801985): III PSEC. De modo geral, os PSEC compunham-se de objetivos, prioridades, programas e projetos destinados aos diferentes aspectos educacionais, abrangendo desde a infraestrutura até a valorização do magistério, em consonância com os ideais de desenvolvimento dispostos nos PND.

\footnotetext{
${ }^{7}$ A denominação ensino primário na Carta de 1967 se converterá em ensino de primeiro grau na lei no 5.692/1971 (CURY, 2008, p. 8).
} 
O III PND, em especial, refletiu um novo cenário marcado pela redução gradativa de influência dos tecnocratas nas questões educacionais, em consonância com o processo de mobilização social e de luta em prol de direitos sociais em curso.

No entanto, ao longo do período em que vigorou o regime civil-militar, diversas reformas educacionais ocorreram com ênfase no pensamento tecnocrático consubstanciados, sobretudo, na aprovação da Lei no 5.540/68 - Reforma Universitária - e Lei no 5.692/71 que reestruturou o funcionamento do ensino e normatizou o ensino profissionalizante. Embora tenham incidindo sobre o funcionamento da educação brasileira, não tiveram por epicentro planos educacionais ou similares (DOURADO, 2016).

Nota-se que o planejamento educacional brasileiro, notadamente após 1930, foi marcado por intermitências de ordem econômica e por questões políticas, cujas disputas por um projeto de sociedade não permitiram avanços para além da formulação do Plano Nacional de Educação no contexto de 1937 e de 1962. Especialmente no que se refere ao direito à educação nas constituições brasileiras, é possível observar diversas mudanças subjacentes a esse direito, considerado o momento histórico, social e político em que se forjou.

Quadro 01: Síntese do direito à educação nas Constituições brasileiras pré 1988.

\begin{tabular}{|c|l|}
\hline Constituição de 1824 & $\begin{array}{l}\text { Elencou a instrução primária como gratuita aos cidadãos, embora a } \\
\text { grande maioria da população fosse constituída por escravos; }\end{array}$ \\
\hline Constituição de 1891 & $\begin{array}{l}\text { Dispôs sobre a laicidade do ensino público, mas não afirmou que a } \\
\text { educação seria obrigatória a todos; }\end{array}$ \\
\hline Constituição de 1934 & $\begin{array}{l}\text { Precedência da família sobre o Poder Público; Introduzida a } \\
\text { obrigatoriedade escolar para o ensino primário; }\end{array}$ \\
\hline Constituição de 1937 & $\begin{array}{l}\text { Restrição à ideia de gratuidade indiscriminada de ensino; Papel do } \\
\text { Estado subsidiário ao direito à educação; }\end{array}$ \\
\hline Constituição de 1946 & $\begin{array}{l}\text { Educação como direito de todos; Ensino ministrado no lar e na escola; } \\
\text { Garantia de serviços auxiliares ou de assistência aos estudantes; }\end{array}$ \\
\hline Constituição de 1967 & $\begin{array}{l}\text { Ensino ministrado no lar na nacolá Ampliação do período obrigatório } \\
\text { de escolarização; Mecanismos de bolsas de estudos restituíveis no } \\
\text { contexto ulterior de ensino; Explicita-se o dever do Estado em garantir } \\
\text { a educação para todos. }\end{array}$ \\
\hline
\end{tabular}

Fonte: Elaboração própria com base em Oliveira (2002).

Nota-se, portanto, que a obrigatoriedade escolar do ensino primário é garantida em nível constitucional a partir de 1934 com 5 (cinco) anos de duração, cuja progressão ocorre no contexto de 1967. A gratuidade do ensino e a influência de diferentes 
concepções acera das instituições responsáveis pela educação escolar figuram nos textos constitucionais, dada as disputas por projetos distintos de sociedade.

Explicitamente, as Constituições brasileiras anteriores à CF/1988 não continham a previsão legal de nenhum mecanismo jurídico com vistas a garantir o direito à educação face a ação ou omissão da família e/ou do Estado, bem como a ausência da educação infantil ( 0 a 5 anos de idade) enquanto constitutiva do direito à educação.

Esse quadro, dado o contexto pré-constituinte nos anos de 1980, dentre outros avanços no campo jurídico, alterou-se significativamente com o advento da CF/1988, cuja previsão de mecanismos jurídicos garantidores do direito à educação possibilitou novos caminhos, inevitavelmente com disputas - como se pretende demonstrar a seguir.

\section{A educação como um direito social no contexto da (re) democratização do país: Constituição Cidadã de 1988}

O contexto dos anos 1980 demarca o fim do consenso dos setores dominantes em torno dos objetivos do desenvolvimento, assim como o aumento das pressões populares pelo reconhecimento integral de seus direitos sociais, políticos e econômicos, cuja a influência da reestruturação global do sistema capitalista provoca alterações objetivas e subjetivas em toda sociedade (FERREIRA, 2013).

A (re) democratização da sociedade brasileira, com o fim da ditadura civil-militar e com o processo constituinte, trouxe avanços consideráveis no que concerne à formalização dos direitos sociais. A CF/1988, resultado de um amplo processo constituinte, é um marco que consagra diversos princípios dando início ao processo de democratização da sociedade e de criação dos espaços públicos.

Publicada no Diário Oficial da União em 05 de outubro de 1988, composta por títulos, capítulos e seções que versam sobre a organização dos poderes e do Estado, competências dos entes federados, etc. em seus 250 (duzentos e cinquenta) artigos, a Constituição Federal de 1988 assegurou diversos princípios advindos da Carta de Goiânia, além de apresentar taxativamente uma gama de direitos e garantias fundamentais com vistas à promoção da dignidade da pessoa humana, cujo caráter é de supremacia face aos demais dispositivos.

O direito à educação no Brasil é reconhecido como um direito fundamental social de tal modo que detém número expressivo de dispositivos em relação aos demais direitos 
sociais. "Esse direito revela em si natureza constitucional dúplice: constitui direito e dever, sincreticamente, englobando o direito do indivíduo de se educar e o dever do Estado, da sociedade e da família em educar" (ALVES, 2018, p.116). Os titulares, sujeitos ativos, prima facie, são as crianças, os jovens, os adultos e idosos observadas suas peculiaridades. No polo passivo, por sua vez, tem-se o Estado enquanto responsável por excelência por sua prestação, consideradas as competências constitucionais dos entes subnacionais.

A compreensão do rol dos direitos sociais exige uma análise conjunta e sistemática das normas constitucionais em sua integralidade, bem como da legislação infraconstitucional e jurisprudências correlatas. No regime jurídico do direito à educação, a obrigação do Estado não se esgota no atendimento material e administrativo conforme previsão constitucional. Isso conduz ao entendimento de que os Poderes Públicos ${ }^{8}$ não podem promover uma evolução reacionária das posições já alcançadas, isso é, retroceder. (RANIERI, 2018).

Depreende-se que a CF/1988 é um marco na questão dos direitos sociais visto abarcar, em seus dispositivos legais, diversas reivindicações sociais cuja regulamentação e materialização estão em curso e sendo disputadas conforme projetos distintos de sociedade. Para Fagnani (2016), o objetivo de construir uma sociedade civilizada, democrática e socialmente justa foi representada com a promulgação da CF/1988 e por isso, representa um marco do processo civilizatório brasileiro. "O novo ciclo democrático inaugurado por ela, associado aos avanços sociais obtidos na década passada, contribuiu para a melhoria do padrão de vida da população, especialmente dos mais pobres" (FAGNANI, 2016, p.70).

Notadamente sobre o Direito à Educação na Carta Magna, têm-se os artigos 205 a 214 que dispõe sobre princípios, atribuições e competências dos entes federados, organização curricular, fontes de financiamento, programas suplementares ao ensino, dentre outras disposições. 0 art. 205 delibera que a educação se reveste de direito e dever: direito de todos e dever do Estado e da família, cuja promoção e incentivo advirá também

\footnotetext{
${ }^{8} \mathrm{~A}$ intervenção do Judiciário, sob esse prisma, em virtude de sua inobservância, faz-se simetricamente em atendimento ao fundamento da dignidade da pessoa humana (CF, art. 1ํ, III). Assim sendo, o não atendimento do direito de crédito em questão qualifica-se como inconstitucionalidade por omissão, ressalvada a ocorrência de justo motivo objetivamente aferível sob invocação da cláusula da reserva do possível (RANIERI, 2018, p.35).
} 
da sociedade com vistas ao desenvolvimento da pessoa, seu preparo para o exercício da cidadania e sua qualificação para o trabalho (BRASIL, 1988).

O direito e dever à educação resguarda-se de princípios próprios que devem ser observados na sua prestação, seja ela na Educação Básica (compreendida a faixa escolar dos 04 aos 17 anos: Educação Infantil, Ensino Fundamental e Ensino Médio), como também no Educação Superior (Graduação e Pós-graduação Lato e Strictu Senso). Dentre os princípios, figura o pluralismo de ideia, a igualdade de condições de acesso e permanência, a liberdade de ensinar, aprender e pesquisar, a gratuidade do ensino, a gestão democrática da educação, além da valorização dos profissionais do magistério.

Paradoxalmente ao caráter social advindo com a promulgação da CF/1988 e expressado nos princípios supracitados, tem-se a ofensiva neoliberal, na década de 1990, de modo diverso ao ocorrido nos países centrais.

Não é um pacto "social-liberal" que sucede, no nosso país, a aliança de hegemonia, mas, contrariamente, é esta última que substitui, na década de 90, o "pacto social-democrático" dos anos 80 [...] enquanto a década de 80 é marcada por um "pacto social" entre os diversos setores democráticos, pressionados por amplos movimentos sociais e classistas (que levou à Constituição de 1988), os anos 90 representam o contexto do desenvolvimento mais explícito da hegemonia neoliberal [...] (MONTAÑO, 2010, p.35-36).

Dessa forma, começa a amadurecer a ideia da (contra) reforma do Estado "operada pela hegemonia neoliberal, que procura reverter as reformas desenvolvidas historicamente por pressão e lutas sociais e dos trabalhadores, tendo seu ponto máximo expresso na Carta de 1988" (MONTAÑO, 2010, p. 29). O neoliberalismo se fortalece contra o Estado de Bem-Estar Social e contra as políticas de estímulo as economias nacionais, de modo a provocar, durante a década de 1990, um esgotamento das funções e instituições de planejamento governamental, haja vista a agenda de reforma do Estado (VIEIRA, 1998).

Nesse contexto, não se pode desconsiderar que o Estado em suas encarnações précapitalista e capitalista, é preeminentemente, como sugere Harvey (2016), uma máquina envolvida em rivalidades e planos geopolíticos e geoeconômicos no cenário mundial. Desse modo, o Estado capitalista estabelece alianças diplomáticas e procura vantagens comerciais e econômicas a fim de garantir o poder de seus líderes e sua própria riqueza. 
Em meados de 1998, a CF/1988 amoldou-se, sobretudo em seu título “Da Ordem Econômica e Financeira", aos preceitos das agências internacionais como Banco Mundial e outros congêneres. Leher (1995) sustenta que a redefinição dos sistemas educacionais situa-se no bojo das reformas estruturais encaminhadas pelo Banco Mundial ${ }^{9}$, isso é, o “Ministério Mundial da Educação dos países periféricos" (p.19).

Cumpre registrar que mudanças organizacionais no Banco possibilitaram maior controle sobre os países tomadores de empréstimos que, entrelaçado ao ideário neoliberal e diante da vulnerabilidade dos países endividados, impôs drásticas reformas liberais. Muitos países geraram dívidas acima da capacidade de pagamento e perderam, por consequência, poder de pressão. 0 Brasil, assim como outros países, submeteu-se aos ditames dos "Novos Senhores do mundo".

As novas exigências requeridas ao Estado brasileiro para o desenvolvimento do capitalismo dizem respeito ao alinhamento político com os demais países de hegemonia neoliberal, aos empréstimos contraídos junto aos organismos internacionais com vistas ao financiamento dos projetos e, por consequência, ao seu monitoramento por aqueles que os financiam (ANDRADE, 2005).

\section{Considerações finais}

A (re) democratização da sociedade brasileira com o processo constituinte trouxe avanços consideráveis no que concerne à formalização dos direitos sociais. A Constituição Cidadã de 1988, resultado de um amplo processo constituinte, é um marco que consagra diversos princípios e uma gama de direitos individuais e coletivos, visto abarcar, em seus dispositivos legais, diversas reivindicações sociais cuja regulamentação e materialização estão em curso e sendo disputadas conforme projetos distintos de sociedade.

Em decorrência da adoção do modelo de Estado Social adotado na CF/1988, há que se resguardar os direitos individuais e direitos sociais e, desse modo, o papel de destaque conferido aos direitos fundamentais desautoriza sua negação e/ou esvaziamento.

Nesse contexto, o direito à educação no Brasil é reconhecido como um direito fundamental social e detém de número expressivo de dispositivos em relação aos demais

\footnotetext{
${ }^{9}$ A participação do Banco deu-se pelo financiamento de um projeto destinado à educação fundamental: o Fundo de Desenvolvimento da Escola (Fundescola), cujo carro chefe foi o Plano de Desenvolvimento da Escola (PDE/Escola), uma modalidade de planejamento gerencial, formulado com a parceria do programa das Nações Unidas para o Desenvolvimento (PNUD). Inicialmente desenvolvido nas regiões Norte, Nordeste e Centro Oeste de 1998 a 2010, foi estendido a outros estados brasileiros (FONSECA, 2016, p. 36).
} 
direitos sociais. Os artigos 205 a 214 da CF/1988 dispõem sobre princípios, atribuições e competências dos entes federados, fontes de financiamento, dentre outras disposições que garantem espaço privilegiado à educação da população brasileira.

Desse modo, a educação é revestida de uma dupla função: direito de todos e dever do Estado e da família. Resguarda-se, portanto, de princípios próprios que devem ser observados na sua prestação, dentre os quais está o pluralismo de ideia, a gestão democrática da educação, a igualdade de condições de acesso e permanência, a liberdade de ensinar, a gratuidade do ensino, dentre outros.

Historicamente o direito à educação no Brasil é atingido pelas intermitências de ordem econômica e político-partidária que, ora lhe permite uma ampliação, ora há obstáculos no tocante à sua universalização. Disputas por projetos distintos de sociedade reverberam nas políticas educacionais e, de modo similar ao ocorrido em outros momentos da história da educação brasileira, têm-se um ataque aos elementos garantidores do financiamento da educação pública, especialmente à vinculação constitucional de recursos.

\section{Referências}

ALVES, Angela Limongi Alvarenga. 0 direito à educação de qualidade e o prncípio da dignidade humana. In: RANIERI, Nina Beatriz Stocco; ALVES, Angela Limongi Alvarenga (Orgs.). Direito à educação e direitos na educação em perspectiva interdisciplinar. São Paulo, SP: USP, 2018. p. 115-146

ANDRADE, Carlos Alberto Nascimento de. Planejamento educacional, neopatrimonialismo e hegemonia política (RN, 1995-2002). São Paulo, SP: Annablume, 2005.

BORDIGNON, Genuíno; QUEIROZ, Arlindo; GOMES, Lêda. o planejamento educacional no Brasil. Brasília: Fórum Nacional de Educação, 2011.

BRASIL. Palácio do Planalto. Constituição da República Federativa do Brasil de 1988. Disponível em:

<http://www.planalto.gov.br/ccivil_03/constituicao/constituicaocompilado.htm>.Acess o em: 19 de junho de 2018.

Palácio do Planalto. Emendas à Constituição. 2019. Disponível em: <http://www.planalto.gov.br/ccivil_03/constituicao/emendas/emc/quadro_emc.htm>. Acesso em: 20 de junho de 2018.

Câmara dos Deputados. C oordenação de publicações. Constituições brasileiras. Série cardernos do museu, n. 4. Disponível em: < https://www2.camara.leg.br/a- 
camara/visiteacamara/cultura-na-camara/copy_of_museu/publicacoes/arquivospdf/Constituicoes\%20Brasileiras-PDF.pdf>. Acesso em: 23 de out. 2020.

Lei no 4.024 de 20 de dezembro de 1961. Fixa as Diretrizes e Bases da Educação Nacional. Disponível em: < https://www2.camara.leg.br/legin/fed/lei/1960-1969/lei4024-20-dezembro-1961-353722-publicacaooriginal-1-pl.html>. Acesso em: 23 de out. 2020 .

Lei no 9.394 de 20 de dezembro de 1996. Estabelece as diretrizes e bases da educação nacional. Disponível em: <http://www.planalto.gov.br/ccivil_03/leis/19394.htm>. Acesso em: 23 de out. 2020.

CURY, Carlos Roberto Jamil. Sistema Nacional de Educação: desafios para uma educação igualitária e federativa. Educação e Sociedade. Vol. 29, N. 105, P.1187-1209. Set./out. 2008.

FAGNANI, Eduardo. 0 golpe de 2016 no Brasil. In: JINKINGS, Ivana; DORIA, Kim; CLETO, Murilo. (Orgs.) Por que gritamos o golpe? Para entender o impeachment e a crise política no Brasil. São Paulo, SP: Boitempo, 2016.

MONTAÑO, Carlos. Terceiro setor e questão social: crítica ao padrão emergente de intervenção social. São Paulo: Cortez, 2010.

FERREIRA, Eliza Bartolozzi. Democracia e tecnocracia no planejamento educacional brasileiro: tensões permanentes na educação do século 21. In: FERREIRA, Eliza Bartolozzi; FONSECA, Marília. (Orgs.) Política e planejamento educacional no Brasil do século 21. Brasília, DF: Liber Livros, 2013.

HARVEY, David. 17 contradições e o fim do capitalismo. 1.ed. São Paulo, SP: Boitempo, 2016.

IANNI, Octavio. Estado e planejamento econômico no Brasil. 6ed. Rio de Janeiro: Civilização brasileira, 1996

LEHER, Roberto. Um novo senhor da educação? A política educacional do Banco Mundial para a periferia do capitalismo. São Paulo: Instituto de Estudos Sociais, 1999. p.19-30.

MARTINS, Angela Maria; PIMENTA, Cláudia Oliveira. Planos Municipais de Educação de regiões metropolitanas em São Paulo: análise de fontes oficiais. Fundação Carlos Chagas. 2013.

NOGUEIRA, Octaviano. A Constituição de 1824. 3.ed. Brasília: Senado Federal, 2012. (Coleção Constituições brasileiras).

OLIVEIRA, Romualdo Portela. 0 direito à educação. In: OLIVEIRA, Romualdo Portela. ADRIÃO. Theresa. Gestão, financiamento e direito à educação: análise da LDB e da Constituição Federal. 2.ed. Xamã. 2002. 
OLIVEIRA, M. dos S. de; SANTELLI, I. H. da S. O direito à educação na ordem constitucional brasileira: texto e contexto

RANIERI, Nina. O direito educacional no sistema jurídico brasileiro. In: Associação Brasileira de Magistrados, Promotores de Justiça e Defensores públicos da infância e adolescência. Justiça pela qualidade na educação. São Paulo: Saraiva, 2018. 

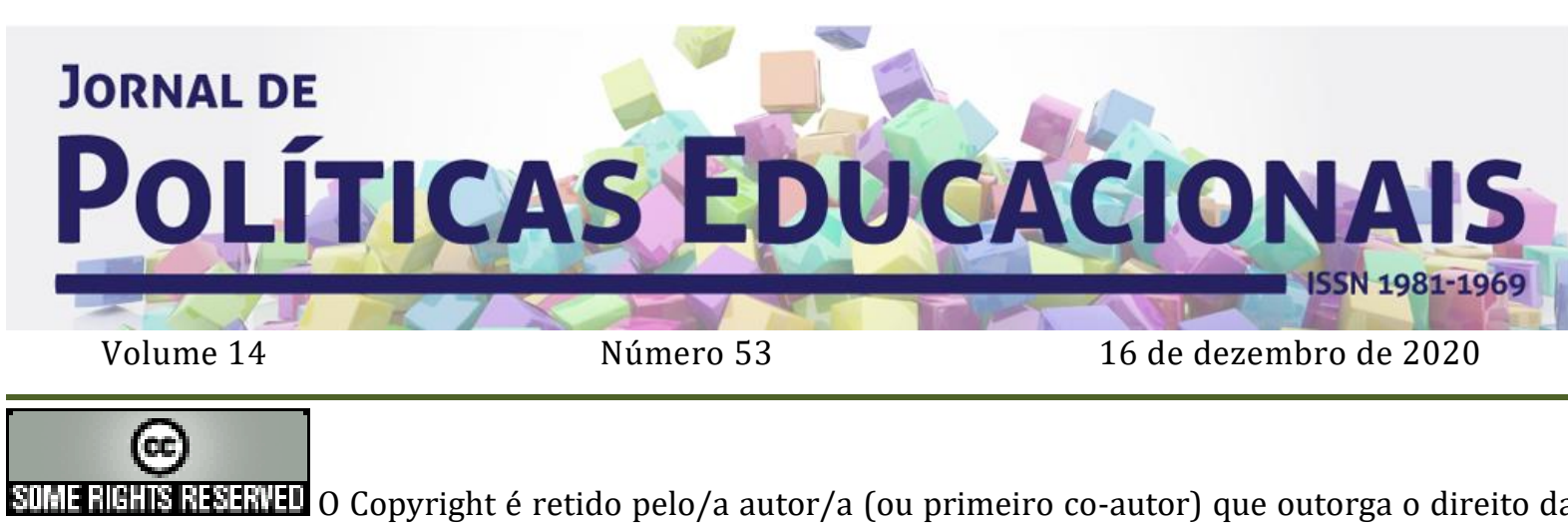

Jight é retido pelo/a autor/a (ou pr primeira publicação ao Jornal de Políticas Educacionais. Mais informação da licença de Creative Commons encontram-se em http://creativecommons.org/licenses/by-nc-nd/2.5. Qualquer outro uso deve ser aprovado em conjunto pelo/s autor/es e pelo periódico.

JoRNAL DE POLÍTICAS EDUCACIONAIS é uma publicação do Núcleo de Políticas Educacionais do Setor de Educação da Universidade Federal do Paraná - NuPE/UFPR, em consórcio com a Linha de Pesquisa em Políticas Educacionais do Programa de Pós-Graduação em Educação - PPGE/UFPR, que aceita colaboração, reservando-se o direito de publicar ou não o material espontaneamente enviado à redação. As colaborações devem ser enviadas ao NuPE/UFPR, conforme orientações contidas nas páginas do periódico na internet: http://revistas.ufpr.br/ipe.

Indexação:

BBE - Biblioteca Brasileira de Educação (MEC/INEP)

Clase (Base de Datos Bibliográfica de Revistas de Ciencias Sociales y Humanidades)

Diadorim - Diretório de Política de Acesso Aberto das Revistas Científicas Brasileiras (IBICT)

Google Scholar

Index Copernicus

Portal de Periódicos (CAPES)

SER - Sistema Eletrônico de Revistas da Universidade Federal do Paraná (SER/UFPR)

Sumários de Revistas Brasileiras (FUNPEC-RP)

DRJI - Directory of Research Journals Indexing

(Periódico integralmente disponível apenas em via eletrônica)

Jornal de Políticas Educacionais / Núcleo de Políticas Educacionais da Universidade Federal do Paraná NuPE/UFPR - v.1, n. 1 (1o semestre de 2007) - Curitiba: NuPE/UFPR.

Volume 14, número 53 - Dezembro de 2020

ISSN 1981-1969

1. Educação - Periódicos. 2. Política Educacional - Periódicos. I. NuPE/UFPR

Comitê Editorial:

Elisângela Scaff (UFPR)

Daniela de Oliveira Pires (UFPR)

Conselho Editorial:

Andréa Barbosa Gouveia (UFPR - Brasil), Cesar Tello (Universidad Nacional Tres Febrero, Argentina), Fernanda Saforcada (Universidad de Buenos Aires - UBA - Argentina), Gladys Beatriz Barreyro (USP Brasil), Gustavo Enrique Fischman, (Arizona State University - USA), Jefferson Mainardes (UEPG - Brasil), João Ferreira de Oliveira (UFG - Brasil), Juca Gil (UFRGS - Brasil), Luiz Souza Júnior (UFPB - Brasil), Ney 
OLIVEIRA, M. dos S. de; SANTELLI, I. H. da S. O direito à educação na ordem constitucional brasileira: texto e contexto

Cristina Monteiro de Oliveira (UFPA - Brasil), Nicolás Bentancur, (Universidad de la República de Uruguay), Robert Verhine (UFBA - Brasil), Rosana Cruz (UFPI - Brasil), Rubens Barbosa Camargo (USP - Brasil), Sebastián Donoso Díaz (Universidad de Talca - Chile), TheresaAdrião (UNICAMP - Brasil), Vera Peroni (UFRGS - Brasil).

Créditos e Agradecimentos:

Revisão de Língua Portuguesa, Abstract e Resumen: PROGRAMA DE APOIO ÀS PUBLICAÇõES CIENTÍFICAS PERIÓDICAS DA UFPR

Arte e diagramação: TIAGO TAVARES (thiagotav@gmail.com)

Jornal de Políticas Educacionais

Universidade Federal do Paraná

Setor de Educação

Núcleo de Políticas Educacionais - NuPE/UFPR

Avenida Sete de Setembro, 2645

$2^{\circ}$ andar, Sala 213

80.230-010 - Curitiba - PR - Brasil

Tel.: 41-3535-6264

jpe@ufpr.br

http://revistas.ufpr.br/jpe 